\title{
Genotype-phenotype correlation in von Hippel-Lindau disease: identification of a mutation associated with VHL type $2 \mathrm{~A}$
}

\author{
F Chen, L Slife, T Kishida, J Mulvihill, S E Tisherman, B Zbar
}

\begin{abstract}
A family with von Hippel-Lindau disease (VHL) type 2A has been shown to have a T to $C$ missense mutation at nucleotide 547 of the VHL gene. This gives further support for the proposal to associate the 547 T to $\mathrm{C}$ mutation with phenotype VHL 2 A.

(F Med Genet 1996;33:716-717)
\end{abstract}

Key words: von Hippel-Lindau disease; genotypephenotype correlation; VHL type $2 \mathrm{~A}$.

Von Hippel-Lindau (VHL) disease (MIM No 199300) is a multisystem, inherited disease characterised by a predisposition to develop retinal angiomas, central nervous system haemangioblastomas, clear cell renal carcinomas, pancreatic cysts, and phaeochromocytomas. ${ }^{1}$ The VHL tumour suppressor gene has been isolated by positional cloning. ${ }^{2}$ Germline mutations were identified in $75 \%$ of 114 US and Canadian VHL families. ${ }^{3}$ Somatic mutations in the VHL gene were found in sporadic clear cell renal carcinomas, ${ }^{4-6}$ sporadic central nervous system haemangioblastoma, ${ }^{7}$ and a sporadic cystadenoma of the epididymis ( $\mathrm{T}$ Wheeler, in preparation). Clinical heterogeneity is a well known feature of VHL ${ }^{8}{ }^{9}$ It was proposed that VHL be classified according to clinical manifestations (table 1 ).$^{310}$ The proposed classification correlates with the type of mutation. ${ }^{11}$ VHL type 1 is caused by nonsense, deletion, microdeletion/insertion, and missense mutations in the VHL gene..$^{11}$ In contrast, VHL type 2 is caused only by missense mutations in the VHL gene. ${ }^{3} 1011$

One large, multigenerational VHL family (3127) of German origin serves as a prototype for a subtype of VHL type 2, VHL type 2A (VHL with phaeochromocytoma without renal cell carcinoma or pancreatic cysts) (table 1). ${ }^{8}$ Affected members of VHL family 3127 had an exon 1 missense mutation T505C that changed a tyrosine to a histidine $(\mathrm{Y} 97 \mathrm{H})$. The T505C mutation has also been found in another, smaller US family, $347,{ }^{3}$ as well as several VHL type $2 \mathrm{~A}$ families from the Black Forest region of Germany. ${ }^{12}$ Analysis of the haplotypes of the disease chromosomes from these families suggests that the US and Black Forest VHL families represent a single, ancestral mutation at nucleotide 505 in the VHL gene. $^{12}$
One of the authors (ST) has studied a large Pennsylvanian phaeochromocytoma family (1190) of German origin for the past 30 years. ${ }^{13}{ }^{14}$ This family contains 19 affected subjects, 19 with phaeochromocytoma, four with retinal angioma, one with central nervous system haemangioblastoma, and none with renal cell carcinoma. Based on these clinical findings, this family has been classified as VHL type 2A. Because VHL family 1190 was classified as VHL type $2 \mathrm{~A}$, and was of German origin, we tested whether this family had a mutation at nucleotide 505 or another distinct mutation. Blood samples from five affected $(4612,4613,4796,4799,4801)$ and seven unaffected members of family 1190 were tested by single strand conformational polymorphism analysis (SSCP) with primers for the three exons of the VHL gene. The exon 1 SSCP labelling reactions were performed as described previously ${ }^{4}$ using primers 9B (5' CAT CTT CTG CAA TCG CAG TCC GCG CGT CGT $3^{\prime}$ ) for the sense strand and primer 101 (5' CCC TGC TGG GTC GGG CCT AAG CGC CGG GCC CGT 3') for the antisense strand. A novel migrating fragment was identified in all five affected members of family 1190 in exon 1 . None of the tested samples from seven unaffected members showed this alteration (fig 1A). DNA from patients 4612 and 4613 of the family was amplified by PCR and subcloned. A T547C (Y111H) mutation was shown in clones derived from patients 4612 and 4613 (fig 1B). Sequencing in both directions confirmed this result. The other three affected subjects (4796, 4799, 4801) were not sequenced. 93

The nucleotide T547C mutation was previously observed in a family (3738) that contains three affected subjects ( $3 / 3$ with phaeochromocytoma and $0 / 3$ with renal cell carcinoma). Because of the small size of family 3738 , it was not possible to assign the 547 mutation to VHL type $2 A$ or $2 B$. Including family 1190,22 affected subjects with the T547C mutation have been identified and 19/22 members had phaeochromocytoma; $0 / 22$ had renal cell carcinoma. (In family 1190, phaeochromocytoma

Table 1 Clinical classification of $V H L$

\begin{tabular}{ll}
\hline Type & Clinical characteristic \\
\hline 1 & Without phaeochromocytoma \\
2 & With phaeochromocytoma \\
A & Without renal cell carcinoma or pancreatic cysts \\
B & With renal cell carcinoma or pancreatic cysts \\
\hline
\end{tabular}


A

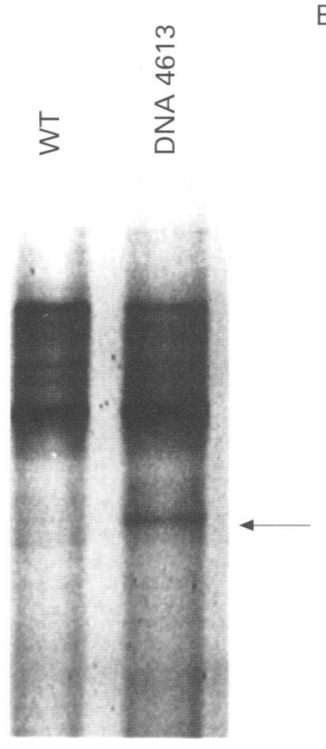

B

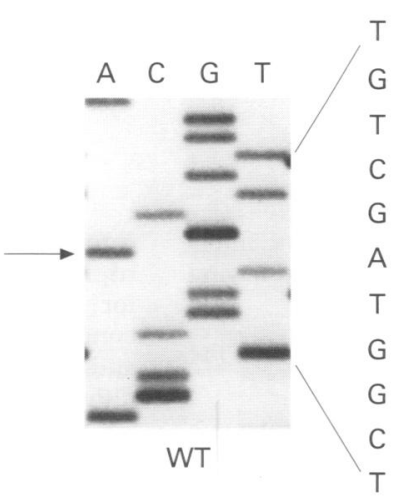

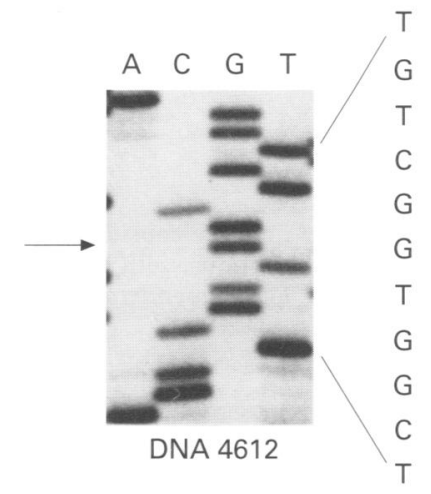

Figure 1 (A) SSCP analysis of a sample from an affected member of family 1190. The arrow indicates the novel migrating fragment. (B) DNA sequencing from wild type and mutant sequences from two affected subjects (4612 and 4613) from family 1190.

and angiomas segregated in $3 / 11$ branches of the family; there was no history of renal cell carcinoma in the 619 members of these three branches.) The $547 \mathrm{~T}$ to $\mathrm{C}$ mutation identified in this large VHL family (1190) enables us to assign this mutation clearly to VHL type $2 \mathrm{~A}$. Both the nucleotide 505 and 547 mutations change a tyrosine to a histidine in exon 1 . The fact that both the nucleotide 505 and 547 mutations change a tyrosine to histidine may provide a clue to the structural changes in the VHL protein that produce phaeochromocytoma but not renal cell carcinomas.

1 Melmon KL, Rosen SW. Lindau's disease: review of the literature and study of a large kindred. $A m \mathcal{F}$ Med

2 Latif F, Tory K, Gnarra J, et al. Identification of the von Hippel-Lindau disease tumor suppressor gene. Science 1993;260:1317-20

3 Chen F, Kishida T, Yao M, et al. Germ line mutations in the von Hippel-Lindau tumor suppressor gene: correlations with phenotype. Hum Mutat 1995;5:66-75.

4 Gnarra J, Tory K, Weng Y, et al. VHL tumor suppressor gene mutations in renal carcinoma tumorigenesis. Nature Genet 1994;7:85-90.
5 Shuin T, Kondo K, Torigoe S, et al. Frequent somatic mutations and loss of heterozygosity of the von Hippel-Lindau tumor suppressor gene in primary renal cell carcinomas. Cancer Res 1994;54:2852-5

6 Whaley JM, Naglich J, Gelbert L, et al. Germ-line mutations in the von Hippel-Lindau tumor suppressor gene are similar to somatic von Hippel-Lindau aberrations in sporadic renal cell carcinomas. Am f Hum Genet 1994;55:1092102.

7 Kanno $\mathrm{H}$, Kondo $\mathrm{K}$, Ito $\mathrm{S}$, et al. Somatic mutations of the von Hippel-Lindau tumor suppressor gene in sporadic central nervous system hemangioblastomas. Cancer Res central nervous

8 Glenn GM, Daniel LN, Choyke P, et al. Von Hippel-Lindau disease: distinct phenotypes suggest more than one mutant allele at the VHL locus. Hum Genet 1991;87:207-10.

9 Neumann HPH, Wiestler OD. Clustering of features of von Hippel-Lindau disease: evidence of a complex genetic locus. Lancet 1991;337:1052-4.

10 Crossey PA, Richards FM, Foster K, et al. Identification of intragenic mutations in the von Hippel-Lindau tumour suppressor gene and correlation with disease phenotype. Hum Mol Genet 1994;3:1303-8.

11 Brauch $\mathrm{H}$, Kishida $\mathrm{T}$, Glavac D, et al. von Hippel-Lindau disease in the Black Forest region of Germany: evidence for a founder effect. Hum Genet 1995;95:551-6.

12 Tisherman SE, Tisherman BG, Tisherman SA, Dunmire S, Levey GS, Mulvihill JJ. Three decade investigation of familial pheochromocytoma. An allele of von HippelLindau disease? Arch Intern Med 1993;153:2550-6.

13 Tisherman DE, Gregg FJ, Danowski TS. Familial pheochromocytoma. $¥ A M A$ 1962;182:152-6.

$14 \mathrm{Zbar}$ B. von Hippel-Lindau disease and sporadic renal cell carcinoma. Cancer Surv 1995;25:219-32. 